\title{
Determination of reasonable power grid asset scale adapting to electric power reform
}

\author{
PENG Jing ${ }^{a}$, LI Ru Ping ${ }^{b}$ and XU Yu Jie \\ State Grid Tianjin Power Economics \&Technology Research Institute, Hedong District, Tianjin \\ 300171, China

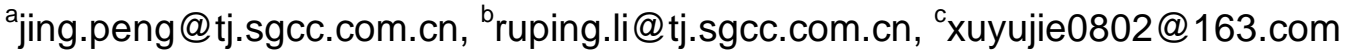

\begin{abstract}
Keywords: electric power reform; incentive compatibility theory; effective assets; regulatory mechanism.

Abstract. In the context of electric power reform, profit model of power grid is undergoing profound changes. The effective assets are the basis of the accounting enterprise's permitted income. So, in order to meet the growing demand for electricity supply and build smart grid, power grid need to arrange the scale of investment reasonably. Based on the incentive compatibility theory, a calculation model of reasonable investment scale of power grid is built in this paper, and third-party regulatory mechanism is introduced to check the investment plans to avoid disorderly investment and resources waste. Then, the government becomes the arbiter to develop regulatory rules more objective.
\end{abstract}

\section{Introduction}

In 2015, in order to further break the monopoly of power grid, a new round of market-oriented reform kicked off. As the key link, transmission and distribution price reform will adhere to the "regulatory cost and reasonable income" principle[1,2], which will cause great challenges on the profitability of power grid.

Transmission and distribution price largely depends on the regulatory cost and effective assets of power grid. In present, the amount of studies about cost regulation is large[3,4], but related research about effective asset is lack. Enlarging and strengthening asset size is the essential road of the power grid. The blind expansion of asset size may lead to asset inflation, increased costs, waste of resources and staff inefficiency. Therefore, it has important theoretical and practical significance to strengthen the investment supervision and determine the effective size of power grid[5].

\section{The application of incentive compatibility theory in reasonable assets accounting}

Incentive compatibility constraint theory means that under the existence of uncertainty and information asymmetry, the agent's behavior may deviate from the expected result of the client due to the different objective function of the agent and the client. When the principal didn't observe the deviation and had no effective supervision and restraint, the agents may pursue their own interests maximize and damage the client's interests. In order to solve this problem, the client need to design a system to bind the interests of the client and agent effectively and encourage the agent to take the most favorable behavior to the client. In this way, the maximize interestsof the client is achieved by the realization of the agent's utility. It's incentive compatibility constraint[6].

Based on the incentive compatibility theory, the government could bind the social welfare with the interests of the power grid and allow the construction of power grid with moderate leading according to the level of socio-economic development and load forecast. Meanwhile, the government should approve the construction projects strictly to avoid blind investment and waste of resources.

Based on incentive compatibility theory, the accounting route of the rational size of the power grid is shown in Figure 1. 


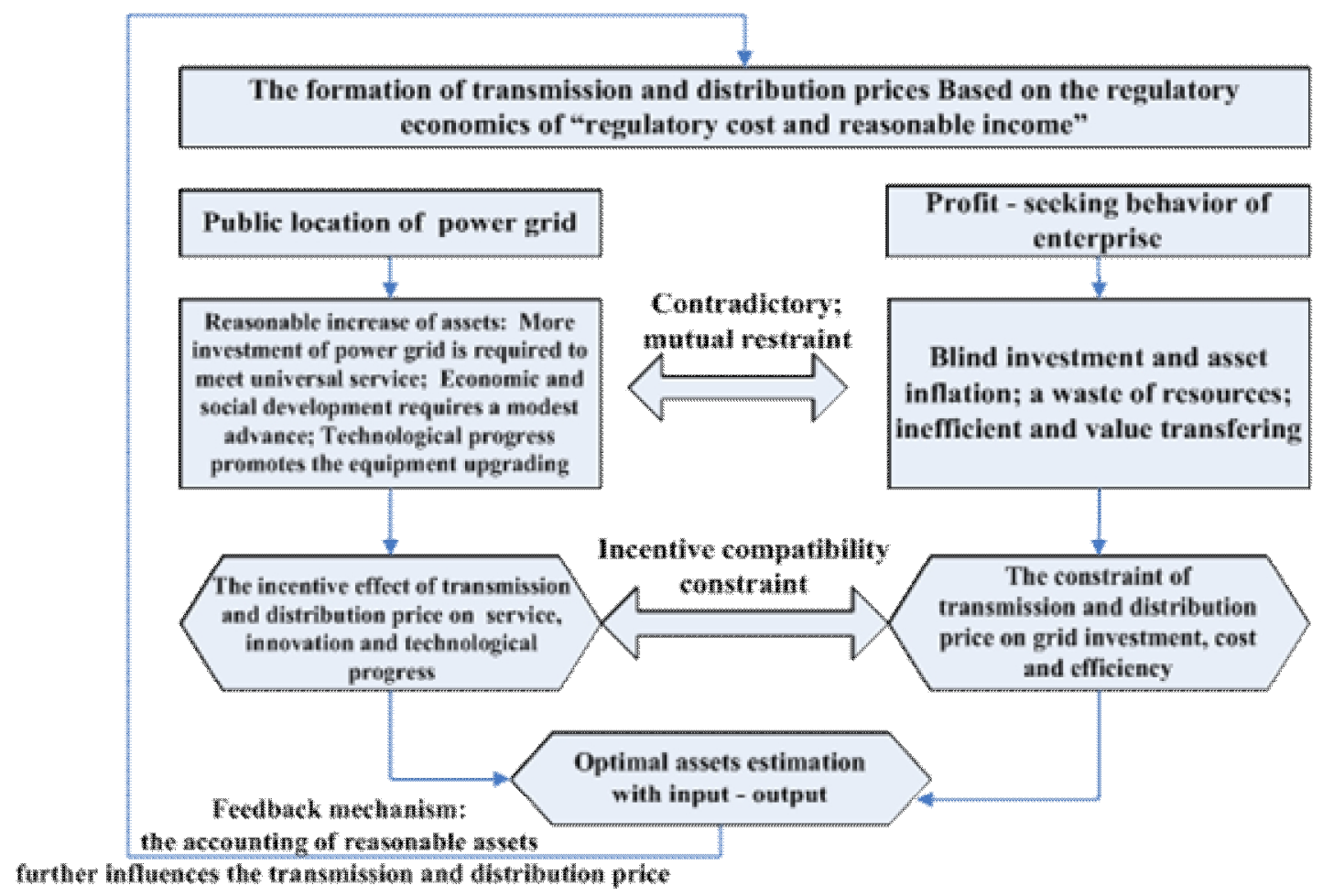

Fig.1 Research on formation mechanism of transmission and distribution pric

\section{Calculation Model of Rational Asset of Power Grid Based on Incentive Compatibility Constraint}

The load growth and higher power quality demands that power grid urgently need to improve the reliability and equipment level. Considering that the original asset has already played its application value and has been strictly defined, this paper mainly studies the reasonable scale of the new investment. Grid asset growth includes two aspects, power grid construction projects that meet the new load and the technological transformation, expansion project that meet the power supply reliability.

\section{New investment that meets the load growth}

The growth of grid investment changes with the change of objective environment, which is mainly affected by the natural load increase and the capacity-to-load ratio.

Based on the mechanism of new investment caused by load growth, a investment estimation model that meets the load growth demand is constructed:

$$
\begin{gathered}
\Delta I_{k}=\sum \Delta L_{k, j} \times i_{k, j} \\
\Delta L_{k, j}=L_{k, j}-L_{k-1, j} \\
L_{k, j}=r_{j} \times\left(Q_{k-1, j}+\Delta Q_{k, j}\right)
\end{gathered}
$$

Where, $\Delta I_{k}$ represents the new investment in year $\mathrm{k} ; \Delta L_{k, j}$ represents the new capacity requirements of $\mathrm{j}$ voltage level in year $\mathrm{k} ; i_{k, j}$ represents the new unit capacity investment of $\mathrm{j}$ voltage level in year $\mathrm{k} ; L_{k, j}$ and $L_{k-1, j}$ represent the capacity in year $\mathrm{k}$ and $\mathrm{k}-1 ; r_{j}$ represents thecapacity-to-load ratio of $\mathrm{j}$ voltage level; $\Delta Q_{k, j}$ represents the load growth of $\mathrm{j}$ voltage level in year $\mathrm{k} ; Q_{k-1, j}$ represents the load demand of $\mathrm{j}$ voltage level in year k-1. 


\section{New investment that meets the technical transformation and expansion}

With the life of transmission and distribution equipment increasing, the equipment tends to aging and the transmission and distribution capacity decreases year by year, which will affect the capacity of power supply. At the same time, the application of new technology and equipment requires that the power grid should constantly update equipment, strengthen technological transformation and expansion scale, gradually replace the aging equipment, to improve the security and stability of power grid. The grid investment estimation model of technology transformation and expansion is as follows:

$$
\begin{gathered}
\Delta I_{k}^{\prime}=\sum L_{k, j} \times i_{k, j}-I_{k} \\
L_{k, j}=r_{j} \times\left(Q_{k-1, j}+\Delta Q_{k, j}\right)
\end{gathered}
$$

Where, $\Delta I_{k}^{\prime}$ represents the investment technological transformation and expansion in the year $\mathrm{k}$; $L_{k, j}$ represents the technological transformation and expansion capacity of $\mathrm{j}$ voltage level in year $\mathrm{k} ; i_{k, j}$ represents the new unit capacity investment of technological transformation and expansion of $j$ voltage level in year $\mathrm{k} ; I_{k}$ represents the original assets of $\mathrm{j}$ voltage level in the year $\mathrm{k} ; r_{j}$ represents the capacity-to-load ratio of new equipment; $Q_{k-1, j}$ represents the load of $\mathrm{j}$ voltage level in the year k-1; $\Delta Q_{k, j}$ represents the load growth of $\mathrm{j}$ voltage level in the year $\mathrm{k}$.

\section{Introduction of third-party supervision in the determination of reasonable assets growth}

In order to supervise the investment scale effectively, the third-party supervision (X) could be introduced by the government to audit and supervise the investment plan. In order to make the third-party supervision have the initiative of supervision, some incentive measure is necessary, such as, the supervisor can get a share of the difference between the investment plan and the real demand, as shown in the following formula:

$$
\begin{gathered}
S=\alpha\left(I_{k}-I_{k, a c t}\right) \\
I_{k}=\Delta I_{k}^{\prime}+\Delta I_{k}
\end{gathered}
$$

Where, $I_{k}$ represents the new investment scale of the power grid; $I_{k, a c t}$ represents the investment calculated by the third-party; $\alpha$ represents the penalty factor.

As its penalty condition, the income of the third-party supervision is paid by the power grid. Then, a complete incentive compatibility mechanism is formed. The power grid only submits the real investment plan to make the deviation $\left(I_{k}-I_{k, a c t}\right)$ infinitely close to 0 , so as not to be punished.

\section{Case Analysis}

In this paper, different voltage levels include 5 categories, such as $500 \mathrm{kV}, 220 \mathrm{kV}, 110 \mathrm{kV}, 35 \mathrm{kV}$, $10 \mathrm{kV}$ and below. Based on the forecast data of one provincial power grid during the 13th Five-Year Plan (2016-2020), the new grid investment scale of different voltages is analyzed and calculated in this paper, according to the demand of power grid capacity and the existing assets. The result is shown in Table 1.

Tab.1 The new investment of fixed assets during the 13th Five-Year Plan (Billion Yuan)

\begin{tabular}{|l|l|l|l|l|l|}
\hline voltage levels & 2016 & 2017 & 2018 & 2019 & 2020 \\
\hline $500 \mathrm{kV}$ & 3.40 & 5.44 & 5.44 & 2.72 & 2.04 \\
\hline $220 \mathrm{kV}$ & 5.40 & 5.13 & 5.67 & 2.97 & 2.43 \\
\hline $110 \mathrm{kV}$ & 3.10 & 7.26 & 7.01 & 7.17 & 7.09 \\
\hline $35 \mathrm{kV}$ & 0.77 & 0.72 & 0.69 & 0.69 & 0.62 \\
\hline $10 \mathrm{kV}$ and below & 21.84 & 19.86 & 18.67 & 17.87 & 19.06 \\
\hline total & 34.51 & 38.41 & 37.48 & 31.42 & 31.24 \\
\hline
\end{tabular}


In general, the total investment scale is in a state of fluctuating growth, that is, the increment firstly increases and then decreases. In particular, the investment scale of $10 \mathrm{kV}$ and below occupies an absolute dominant position, which is related to the "Four trillion distribution network transformation plan"in China. However, the investment scale of $35 \mathrm{kV}$ is very small, which is related to the present situation of marginalization.

\section{Some suggestion under the third-party supervision}

According to the characteristic and processe of the third-party supervision, some suggestion is put forward as follows in this paper.

(1) Divide the assets scale of different voltage levels reasonably and restrain invalid investment. On the one hand, according to the grid topology, improve the pertinence and effectiveness of asset calculation. On the other hand, taking the regional economic development, technological progress, and so on into account, determine the reasonable asset scale that meet the load growth to avoid invalid investment.

(2) Change the government function and clear regulatory responsibilities of all parties. Under the traditional regulatory model, the government is a participant in the game of interest. The rusult of supervision is poor, because of the opaque information. Through the transformation of government function, clear the responsibilities and obligations of the government and third-party regulatory body, develop more transparent regulatory rules to improve the regulatory effect.

\section{Conclusions}

In the transmission and distribution price reform, the regulatory cost and reasonable income are important parts of power grid allowable income. In order to avoid the disorderly investment of the power grid, the assets expansion and waste of resource, a calculation model of reasonable investment scale of power grid based on the incentive compatibility theory is built in this paper. The government becomes the arbiter to develop regulatory rules more objective by the third-party supervision mechanism.

\section{References}

[1] National Development and Reform Commission. Several Opinions on Further Deepening Power System Reform[EB/OL].2015.4.10,http://www.sdpc.gov.cn/.

[2] WANG Dongrong, GUAN Lei, ZENG Ming, et al. Summary of international Power Transmission Pricing Mechanisms and Their Enlightenment to China[J].Electric Power Technologic Economics,2005,17(3):59-65.

[3] WAN Shan. Electric power transmission and distribution cost supervision and key problem in China[J].Journal of Shanghai Management Science,2012,34(6):101-106.

[4] LI Ang, XIA Qing, ZHONG Haiwang. Method of Third Party Supervision on Transmission and Distribution Costs[J]. Automation of Electric Power System.2016,40(10):1-7

[5] Loeb M, Magat W A. A Decentralized Method for Utility Regulation[J]. Journal of Law \& Economics, 1979, 22(2):399-404.

[6] JJ Laffont, J Tirole. A theory of incentives in procurement and regulation[M].MIT Press, 1993, 105(428). 